\title{
PENGARUH JARAK TANAM PADA PERTUMBUHAN TIGA JENIS MERANTI DI HUTAN PENELITIAN HAURBENTES
}

( The Effect of spacing on the growth of three meranti species in Haurbentes Forest Research)

Oleh/By :

\section{A.Syaffari Kosasih dan/and Nina Mindawati}

Pusat Litbang Peningkatan Produtivitas Hutan

Kampus Badan Litbang Kehutanan, Jl.Gunung Batu No. 5, Bogor,

Telp.(0251) 8631238, Fax . (0251)7520005

Emailsafari_silvik@yahoo.co.id danninapulp@yahoo.co.id

\begin{abstract}
Defining the most suitable planting spacing in plantation forest is usually aimed at producing straight uniform stem, healthy and high economic value of forest stand. Experiment was conducted to determine influence of spacing and tree species of Shorea leprosula, S.mecistopteryx, and S.selanica on height and diameter growth of 13 years old plantation. This experiment was arranged in a completely randomized design with $2 \times 3$ factorial design where treatment $A$ was spacing and treatment $B$ was meranti species. There were two replications in each treatment combination and there were 10 trees for each replication. The results showed that there were no influence of spacing (A), species $(B)$ and their interaction (AB) on the growth. However comparing with other meranti species S.leprosula grew better. Average tree growth of $2 m \times 3 m$ spacing for S.leprosula was $14.2 \mathrm{~m}$ height and $24.7 \mathrm{~cm}$ diameter. S.selanica $16.1 \mathrm{~m}$ height and $20.8 \mathrm{~cm}$ diameter., S.mecistopteryx $13.7 \mathrm{~m}$ height and $20.6 \mathrm{~cm}$ diameter. For $3 \mathrm{~m} \times 3 \mathrm{~m}$ spacing average height of S.leprosula was $13.0 \mathrm{~m}$ and $27.8 \mathrm{~cm}$ in diameter., S.selanica $12,8 \mathrm{~m}$ height and 22,0 cm diameter and S. mecistopteryx $14.5 \mathrm{~m}$ and $19.9 \mathrm{~cm}$ for height and diameter.
\end{abstract}

Keyword : forest plantation, growth, spacing, meranti species

\begin{abstract}
ABSTRAK
Penetapan jarak tanam pada pembangunan hutan tanaman dimaksudkan untuk menghasilkan tegakan hutan yang memiliki bentuk batang yang lurus, sehat dan bernilai ekonomi tinggi seperti pada tanaman dan tiga jenis meranti merah yaitu Shorea leprosula, S. mecistopteryx dan S. selanica untuk tujuan menghasilkan kayu pertukangan. Dengan tujuan untuk mengetahui pengaruh jarak tanam dan jenis tanaman, terhadap pertumbuhan tinggi dan diameter, dilakukan penelitian pada tanaman berumur 13 tahun dengan menggunakan Rancangan Acak Lengkap (RAL) yang disusun secara faktorial 2 × 3 dimana perlakuan A berupa jarak tanam 2 macam dan perlakuan $\mathrm{B}$ adalah 3 jenis tanaman meranti. Tiap kombinasi perlakuan terdiri dari 10 pohon contoh dan diulang sebanyak dua kali. Hasil penelitian menunjukkan bahwa pertumbuhan S.leprosula lebih baik dibanding kedua jenis lainnya. Rata-rata pertumbuhan tanaman dengan jarak tanam $3 \mathrm{~m}$ x $2 \mathrm{~m}$
\end{abstract}


untuk jenis $S$. leprosula adalah $14,2 \mathrm{~m}$ tinggi dan berdiameter $24,7 \mathrm{~cm} ; S$. selanica $16,1 \mathrm{~m}$ dan 20,8 $\mathrm{cm} ;$ S. mecistopteryx $13,7 \mathrm{~m}$ dan 20,6 cm. Pada jarak tanam $3 \mathrm{~m}$ x $3 \mathrm{~m}$ S. leprosula rata-rata tinggi $13,0 \mathrm{~m}$ dengan diameter $27,8 \mathrm{~cm}$; S.selanica rata-rata tinggi $12,8 \mathrm{~m}$ dengan diameter $22,0 \mathrm{~cm}$; S. mecistopteryx rata-rata tinggi $14,5 \mathrm{~m}$ dengan diameter $19,9 \mathrm{~cm}$.

Kata Kunci : hutan tanaman, pertumbuhan, jarak tanam, meranti

\section{PENDAHULUAN}

Hutan alam produksi di Indonesia yang pada mulanya memiliki jenis-jenis kayu yang berkualitas dan bernilai tinggi pada tahun 1970 s/d 1990 kini fenomenanya jadi terbalik akibat berbagai kerusakan seperti maraknya illegal logging, kebakaran, peladangan serta penggunaan lain yang tidak terkendali. Fenomena ini terlihat dari menurunnya luas hutan alam produksi yang dikelola dengan sistem tebang pilih dari 59,6 juta hektar pada tahun 1990 menjadi 28,7 hektar pada tahun 2007 sehingga produksi kayu bulat turun dari 28 juta $\mathrm{m}^{3} /$ tahun menjadi 9,1 juta $\mathrm{m}^{3}$ pertahun Hal lain yang menjadikan rendahnya produksi karena tiap pertumbuhan kayu dari hutan alam produksi, terbilang sangat kecil yaitu sekitar $1 \mathrm{~m}^{3} /$ ha pertahun (Departemen Kehutanan, 2010).

Sebagai upaya untuk melestarikan dan meningkatkan potensi kayu dari hutan alam produksi tersebut di atas, dapat dilakukan dengan membangun Hutan Tanaman Industri (HTI) sebagaimana dikemukakan oleh para pakar dalam Lokakarya Pembangunan Timber Estates di Fakultas Kehutanan, Institut Pertanian Bogor pada tahun 1984, namun sampai tahun 2010 HTI yang banyak dibangun masih untuk keperluan industri pulp dan kertas, yang mengembangkan jenis-jenis berdaur pendek seperti Eucalyptus spp dan Acacia spp. Data terahir kedua jenis penghasil pulp tersebut sudah ditanam lebih dari 3 juta hektar, sedangkan jenis-jenis kayu pertukangan yang sudah terkenal di dalam maupun di luar negeri serta bernilai tinggi seperti jenis-jenis meranti (Shorea spp), masih kurang mendapat dukungan dari para pengusaha industri kehutanan.

Rendahnya produktivitas, terbatasnya sumber benih maupun bahan tanaman lainnya dari jenis-jenis Shorea yang unggul serta persyaratan tumbuh yang unik (toleran dan semi toleran) menyulitkan para pengusaha untuk mengembangkannya menjadi HTI kayu pertukangan, hingga tahun 2010 baru terbangun puluhan ribu hektar saja dengan tehnik Silvikultur Intensif yang digagas oleh Prof Soekotjo dkk pada tahun 2004 dalam seminar bertema "Visi Silvikulturis Indonesia Menyongsong Kehutanan 2045". Hasil yang diharapkan dari penerapan teknik Silvikultur Intensif pada hutan alam produksi adalah diperolehnya produk kayu bulat jenis Shorea spp sebesar $200 \mathrm{~m}^{3}$ perhektar dalam jangka waktu / daur selama 30 tahun.

Konsep utama dari Silvikultur Intensif tersebut adalah meningkatkan produktivitas hasil hutan yang berupa kayu melalui (1) penggunaan bibit unggul jenis Shorea (2) manipulasi lingkungan (3) perlindungan tanaman dari hama dan penyakit (Soekotjo 2006). Terdapat beberapa 
konsep teknik silvikultur untuk meningkatkan produktivitas kayu, salah satunya adalah pengaturan jarak tanam.

Pengaturan jarak tanam pada pembangunan hutan tanaman dimaksudkan untuk mencegah terjadinya percabangan dan meningkatkan kualitas batang, sehingga hutan tanaman yang terbentuk akan berproduksi secara optimum sesuai dengan tujuannya (Daryadi dan Hardjono, 1972 ; Sumarna dan Harbagung 1988 ; Kustiawan dan Sutisna, 1989; Nyland, 1996).

Jarak tanam mengatur populasi tanaman dan koefisien penggunaan cahaya, terjadi kompetisi antar individu tanaman dalam penggunaan air dan hara sebagaimana dilaporkan oleh Soebiakto et.al (2002) pada tanaman Shorea di Leuwiliang, Bogor dari jarak tanam $3 \mathrm{~m} \times 2 \mathrm{~m} ; 3 \mathrm{~m}$ x $3 \mathrm{~m}, 3 \mathrm{~m} \times 4 \mathrm{~m}, 4 \mathrm{~m} \times 4 \mathrm{~m}$ dan $5 \mathrm{~m} \times 5 \mathrm{~m}$ ternyata jarak tanam $3 \mathrm{~m} \times 2 \mathrm{~m}$ memilikii pertumbuhan yang terbaik. Pada tanaman karet berdasarkan penelitian yang dilaporkan Kuswanhadi dan Boerhandy (1996) volume kayu tertinggi dihasilkan pada tanaman dengan jarak 4 m x 3 m dibandingkan dengan jarak $3 \mathrm{~m} \times 3 \mathrm{~m}$ dan $5 \mathrm{~m} \times 3 \mathrm{~m}$.

Dengan pertimbangan tersebut dilakukan penelitian pengaruh perbedaan jarak tanam pada 3 jenis tanaman meranti yang telah berumur 13 tahun di Kawasan Hutan Dengan Tujuan Khusus (KHDTK) Haurbentes, Bogor dengan tujuan untuk mengetahui ada tidaknya perbedaan pertumbuhan tinggi dan diameter akibat perlakuan perbedaan jarak tanam.

\section{BAHAN DAN METODE}

\section{A. Lokasi Penelitian}

Penelitian dilakukan di Hutan Penelitian Haurbentes, Kecamatan Jasinga, Kabupaten Bogor. Plot terletak $60 \mathrm{~km}$ di sebelah barat, dengan ketinggian antara 200 - $300 \mathrm{~m}$ di atas permukaan laut (dpl). Bentuk lapangan berbukit-bukit, beriklim basah dengan curah hujan rata-rata $4.276 \mathrm{~mm}$ per tahun dalam 187 hari hujan (Masano, 1991). Berdasarkan klasifikasi Schmidt dan Ferguson (1951) termasuk dalam tipe curah hujan A.

Jenis tanah di areal penelitian adalah podsolik merah kuning, yang berkembang dari bahan induk vulkanik masam, bertekstur tanah liat, struktur gumpal dan bereaksi masam (pH 4 - 6) dengan kandungan bahan organik $\mathrm{P}_{2} \mathrm{O}_{5}, \mathrm{~K}_{2} \mathrm{O}$ dan nitrogen rendah.

\section{B. Bahan Penelitian}

Bahan penelitian adalah hutan tanaman meranti jenis Shorea Leprosula, S. mecistopteryx dan $S$. selancia berumur 13 tahun dengan jarak tanam $3 \mathrm{~m}$ x $2 \mathrm{~m}$ dan $3 \mathrm{~m} 3 \mathrm{~m}$. masing-masing jenis ditanam dengan luas 0,25 dan diulang sebanyak 3 kali.

Adapun alat-alat yang didunakan adalah harga meter, caliper, meteran. galah serta alat tulis. 


\section{Metode}

1. Rancangan Penelitian

Rancangan yang digunakan dalam penelitian ini adalah acak lengkap yang disusun secara faktorial dimana jarak tanaman sebagai perlakuan $\mathrm{A}(\mathrm{A} 1=3 \times 2 \mathrm{~m} ; \mathrm{A} 2=3 \times 3 \mathrm{~m})$ dan perlakuan B jenis tanaman $(\mathrm{B} 1=\underline{\text { S.leprosula }} ; \mathrm{B} 2=\underline{\text { S. selanica }} ; \mathrm{B} 3=\underline{\text { S. mecistopteryx }})$ dengan 3 kali ulangan. Setiap ulangan terdiri atas 10 pohon contoh, sehingga jumlah pohon yang diamati seluruhnya adalah 180 pohon. Parameter yang diukur adalah diameter dan tinggi pohon dan untuk pendugaan volume digunakan rumus :

$\mathrm{V}=1 / 4 \Pi(\mathrm{D})^{2} \mathrm{X} \mathrm{T}$ X f dimana $\mathrm{D}=$ diameter, $\mathrm{T}=$ tinggi bebas cabang dan $\mathrm{f}=$ angka bentuk 0,7 (Direktorat Jenderal Kehutanan, 1976).

\section{Analisis Data}

Data hasil pengukuran dianalisis dengan menggunakan keragaman, untuk mengetahui variasi antar jenis dan jarak tanam. Apabila terdapat perlakuan atau kombinasi perlakuan yang berpengaruh nyata selanjutnya diuji dengan metode Duncan (Gomez \& Gomez, 1984 ).

\section{HASIL DAN PEMBAHASAN}

\section{A. Tinggi dan Diameter}

Jarak tanam dimaksudkan untuk mengatur banyaknya pohon dalam satu bidang lahan guna mendapatkan produktivitas yang tinggi serta membentuk batang bebas cabang tinggi dan lurus sehingga kualitasnya meningkat. Dalam penelitian ini diketahui bahwa ketiga jenis Shorea sampai dengan tanaman berumur 13 tahun perlakuan jarak tanam, jenis tanaman, maupun kombinasinya tidak berpengaruh pada pertumbuhan tinggi. Hal tersebut menandakan bahwa tidak terjadi persaingan hara, air maupun sinar matahari. Demikian juga pertumbuhan diameter tanaman sampai umur 13 tahun belum terpengaruh oleh jarak tanam maupun kombinasinya, tetapi jenis tanaman berpengaruh nyata. Hasil analisis sidik ragam tertera pada Tabel 1. 
Tabel (Table) 1. Sidik ragam pengaruh jenis dan jarak tanam pada ukuran tinggi (m) dan diameter (Variance Analysis on the effect of species and spacing to tree height and diameter)

\begin{tabular}{|l|c|c|}
\hline \multirow{2}{*}{$\begin{array}{c}\text { Sumber variasi } \\
\text { (Source of variation) }\end{array}$} & \multicolumn{2}{|c|}{ F-hitung ( F-Calc) } \\
\cline { 2 - 3 } & Tinggi (Height) & $\begin{array}{c}\text { Diameter } \\
\text { (Diameter) }\end{array}$ \\
\hline Jarak tanam ( Spacing ) A & $0,96^{\text {th }}$ & $2,92^{\text {th }}$ \\
\hline Jenis (Species) B & $0,14^{\text {tn }}$ & $29,86^{* *}$ \\
\hline Faktorial (Factorial) AXB & $0,89^{\text {tn }}$ & $2,63^{\text {tn }}$ \\
\hline & & \\
\hline
\end{tabular}

Keterangan : (Remark) : tn $=$ Tidak nyata $($ not significant) $; * *=$ Nyata $($ Significant) pada tarap P 0,05 .

Penelitian yang dilakukan oleh Masano (1991), melaporkan bahwa jarak tanam berpengaruh nyata pada pertumbuhan tanaman Eucalyptus deglupta, E. alba dan Pinus merkusii karena adanya persaingan cahaya matahari. Hal yang sama dilaporkan Effendi dan Bachtiar(1991) bahwa jarak tanam pada tanaman bakau-bakauan (Rhizophora) $2 \mathrm{~m}$ x $1 \mathrm{~m}$ berbeda pertumbuhan tingginya dengan jarak tanam 3 m x 2 m. Demikian juga Nyland (1996) melaporkan bahwa jenis Pinus penderosa pada umur 12 tahun dengan jarak tanam $4 \mathrm{~m} \mathrm{x} 3$ m riapnya 1,5 kali dibandingkan jarak tanam 2 m x 2 m. Sedangkan pada tanaman bambu hasil penelitian Sutiyono (2007) diketahui bahwa jarak tanam berpengaruh pada jumlah batang per rumpun sampai umur 1 tahun, tetapi tidak berpengaruh setelah tanaman berumur 2 dan 3 tahun. Untuk ketiga jenis meranti dalam penelitian ini ternyata jarak tanam $3 \mathrm{~m}$ x $2 \mathrm{~m}$ dan $3 \mathrm{~m}$ x $3 \mathrm{~m}$ sampai dengan umur 13 tahun, belum mempengaruhi pertumbuhan tinggi. Hal tersebut menandakan tidak ada persaingan diantara ketiga jenis dalam memperoleh cahaya, hara maupun air untuk pertumbuhan tinggi.

Pertumbuhan diameter yang cepat, adalah indikator tingginya produksi tanaman, hal mana dapat diperoleh dengan mengatur jarak tanam dan penetapan jenis tanaman. Hasil penelitian antara ketiga jenis tanaman Shorea pada umur 13 tahun dan jarak tanam tertera pada salah satu analisis sidik ragam sebagaimana Tabel 1 diketahui bahwa jarak tanam $3 \mathrm{~m}$ x $2 \mathrm{~m}$ dan $3 \mathrm{~m}$ x $3 \mathrm{~m}$ tidak berpengaruh pada pertumbuhan diameter ketiga jenis meranti pada umur 13 tahun. Demikian juga pada kombinasi perlakuan jarak tanam dan jenis, tetapi terdapat pengaruh jenis tanaman yang sangat nyata pada pertumbuhan diameter. Untuk mengetahui perbedaan pertumbuhan diameter ketiga jenis meranti tersebut, selanjutnya diuji dengan uji Duncan sebagaimana tercantum pada tabel berikut. 
Tabel (Tabel) 2. Rata-rata diameter 3 jenis pohon Shorea umur 13 tahun (Average diameter of 3 Shorea species at age of 13 years.

\begin{tabular}{|c|l|c|}
\hline $\begin{array}{c}\text { No. } \\
(\text { Number })\end{array}$ & \multicolumn{1}{|c|}{$\begin{array}{c}\text { Jenis Tanaman } \\
\text { (Species) }\end{array}$} & $\begin{array}{c}\text { Rata-rata Diameter } \\
\text { (Average Diameter) }\end{array}$ \\
\hline 1. & Shorea leprosula & $26,300^{\mathrm{a}}$ \\
2. & S. selanica & $21,433^{\mathrm{b}}$ \\
3. & S. mecistopteyx & $20,767^{\mathrm{b}}$ \\
\hline
\end{tabular}

Catatan : Angka-angka dalam kolom yang diikuti oleh huruf yang sama, tidak berbeda nyata pada taraf $\mathrm{P}<0,05$ (number in columns followed by different of letters are insignificantly different on $P<0,05$ level)

Dari uji Duncan ternyata jenis Shorea leprosula lebih unggul dengan rataan 26,30 cm berbeda dengan pertumbuhan $S$. selanica dengan rataan $21,43 \mathrm{~cm}$ dan $S$. mecistopteryx dengan rataan $20,76 \mathrm{~cm}$ pada umur 13 tahun.

Hasil yang sama dalam pertumbuhan diameter Shorea leprosula dilaporkan oleh Subiakto (2002) sebesar $8 \mathrm{~cm}$ pada umur 3 tahun di Leuwiliang, Bogor. Sedangkan di Parawang, Riau, berdiameter $4 \mathrm{~cm}$ pada umur 2 tahun. Hasil uji jenis pada beberapa Shorea umur 2,5 tahun dilaporkan Na'iem dan Soekotjo (2006) dalam rangka penerapan silvikultur intensif di beberapa HPH bahwa jenis $S$. parvifolia unggul dalam kecepatan tumbuh dibanding jenis Shorea lainnya. dalam uji keturunan jenis $S$. leprosula sudah mencapai tinggi 5,4 m pada umur yang sama.

\section{B. Rata-rata Volume Pohon Berdiri}

Dugaan rata-rata volume per pohon berdiri (standing stock) dari ketiga jenis meranti yang ditanam dengan jarak $3 \mathrm{~m} \times 2 \mathrm{~m}$ dan $3 \mathrm{~m} \times 3 \mathrm{~m}$ per hektar seperti pada Tabel 3 .

Tabel (Table) 3. Dugaan volume kayu ketiga jenis meranti dengan jarak tanam $3 \mathrm{~m} \times 2 \mathrm{~m}$ dan $3 \mathrm{~m} \times 3 \mathrm{~m}$ (Wood volume estimation of three meranti species with $3 \mathrm{~m} \times 2 \mathrm{~m}$ and 3 mx 3 m spacing)

\begin{tabular}{|c|c|c|c|c|c|}
\hline \multirow{2}{*}{$\begin{array}{c}\text { No. } \\
\text { (Number) }\end{array}$} & \multirow{2}{*}{$\begin{array}{c}\text { Jenis Tanaman } \\
\text { (Tree species) }\end{array}$} & \multirow{2}{*}{$\begin{array}{c}\text { Ulangan } \\
\text { (Replication) }\end{array}$} & $\begin{array}{c}\text { Jumlah } \\
\text { pohon sample } \\
\text { (Number of } \\
\text { tree sample) }\end{array}$ & \multicolumn{2}{|c|}{$\begin{array}{c}\text { Jarak tanam } \\
\text { (Spacing) }\end{array}$} \\
\cline { 5 - 7 } & S. leprosula & 1 & 10 & $0,295 \mathrm{~m}^{3}$ & $0,277 \mathrm{~m}^{3}$ \\
\hline 1 & & 2 & 10 & $0,338 \mathrm{~m}^{3}$ & $0,358 \mathrm{~m}^{3}$ \\
\hline & & 3 & 10 & $0,242 \mathrm{~m}^{3}$ & $0,320 \mathrm{~m}^{3}$ \\
\hline
\end{tabular}




\begin{tabular}{|c|l|c|c|c|c|}
\hline $\begin{array}{c}\text { Rata-rata } \\
\text { (Average) }\end{array}$ & & 1 & 30 & $0,292 \mathrm{~m}^{3}$ & $0,318 \mathrm{~m}^{3}$ \\
\hline 2 & S. selanica & 2 & 10 & $0,307 \mathrm{~m}^{3}$ & $0,286 \mathrm{~m}^{3}$ \\
\hline & 3 & 10 & $0,260 \mathrm{~m}^{3}$ & $0,275 \mathrm{~m}^{3}$ \\
\hline $\begin{array}{c}\text { Rata-rata } \\
\text { (Average) }\end{array}$ & S. mecistoptryx & 1 & 30 & $0,254 \mathrm{~m}^{3}$ & $0,293 \mathrm{~m}^{3}$ \\
\hline 3 & 2 & 10 & $0,202 \mathrm{~m}^{3}$ & $0,269 \mathrm{~m}^{3}$ \\
\hline & 3 & 10 & $0,275 \mathrm{~m}^{3}$ & $0,331 \mathrm{~m}^{3}$ \\
\hline $\begin{array}{l}\text { Rata-rata } \\
\text { (Average) }\end{array}$ & & & 30 & $0,274 \mathrm{~m}^{3}$ & $0,291 \mathrm{~m}^{3}$ \\
\hline
\end{tabular}

Dari Tabel 3 terlihat bahwa potensi kayu ketiga jenis meranti sampai dengan umur 13 tahun yang ditanam dengan jarak $3 \mathrm{~m}$ x 2 m memiliki potensi terbaik, hal tersebut karena banyaknya pohon yang ditanam per hektar lebih banyak yaitu 1650 pohon untuk jarak tanam $3 \mathrm{~m}$ x $2 \mathrm{~m}$, rata-rata per pohon untuk jenis $S$. leprosula sebesar $0,292 \mathrm{~m}^{3} ;$ S. selanica sebesar $0,254 \mathrm{~m}^{3}$ dan $S$. mecistopteryx sebesar $0,291 \mathrm{~m}^{3}$. Dengan perkiraan hanya 50 persen tanaman yang tumbuh, maka volume kayu untuk jenis $S$. leprosula dengan jarak tanam $3 \mathrm{~m}$ x $2 \mathrm{~m}$ sebesar $240 \mathrm{~m}^{3}$ dan untuk jarak tanam $3 \mathrm{~m}$ x $3 \mathrm{~m}$ sebesar $175 \mathrm{~m}^{3}$, untuk jenis $S$. mecistopteryx untuk jarak tanam $3 \mathrm{~m}$ x $2 \mathrm{~m}$ sebesar $226 \mathrm{~m}^{3}$ dan untuk $3 \mathrm{~m}$ x $3 \mathrm{~m}$ sebesar $160 \mathrm{~m}^{3}$, jenis S. selanica volume tegakan pada jarak tanam $2 \mathrm{~m}$ x $3 \mathrm{~m}$ sebesar $209 \mathrm{~m}^{3}$ dan pada jarak tanam $3 \mathrm{~m}$ x $3 \mathrm{~m}$ sebesar $161 \mathrm{~m}^{3}$. Taksiran besaran volume kayu yang dihasilkan dari penelitian ini, tidak jauh berbeda dari taksiran volume kayu yang akan dihasilkan pada penerapan teknik Silvikultur Intensif di hutan alam produksi yaitu sebesar $200 \mathrm{~m}^{3}$ perhektar dengan daur 30 tahun (Soekotjo dan Raharjo, 2011). Secara alami menurut Rudjiman dan Adriyanti (2002), pertumbuhan jenis S. leprosula; S. selanica dan S. mecistopteryx dapat tumbuh hingga lebih dari $60 \mathrm{~m}$ tingginya dan dapat berdiameter $175 \mathrm{~cm}$, seperti di Pulau Kalimantan dan Sumatera sedangkan S. selanica di Maluku.

Penelitian cepat lambatnya pertumbuhan suatu tegakan menurut Herbagung (1991) merupakan resultanta dari faktor-faktor genetifk, lingkungan dan teknik pengelolaan, dalam penelitian ini terlihat bahwa yang dominan mempengaruhi produktivitas adalah jarak tanam sebagai faktor pengelolaan yang menghasilkan volume kayu yang lebih baik sampai dengan umur 13 tahun. Hal yang sama dilaporkan oleh Kustiawan dan Sutisna (1989), pada tanaman Acacia manginum 
umur 4 tahun pada jarak tanam $2 \mathrm{~m}$ x $2 \mathrm{~m}$ bervolume $103 \mathrm{~m}^{3} / \mathrm{ha}, 3 \mathrm{~m}$ x $3 \mathrm{~m}$ sebesar $89 \mathrm{~m}^{3} / \mathrm{ha}$ dan $4 \mathrm{~m} \mathrm{x} 4 \mathrm{~m}$ sebesar $81 \mathrm{~m}^{3} / \mathrm{ha}$. Hal yang sama dilaporkan Kuwwanhadi dan Boerhendy (1996) hasil penelitiannya pada HTI karet Jarak tanam 4 m x 3 m menghasilkan volume kayu yang lebih banyak dibandingkan jarak tanam $5 \mathrm{~m} \times 5 \mathrm{~m}$.

\section{KESIMPULAN DAN SARAN}

\section{A. Kesimpulan}

1. Jarak tanam $3 \mathrm{~m}$ x $2 \mathrm{~m}$ dan $3 \mathrm{~m}$ x $3 \mathrm{~m}$ pada tanaman Shorea leprosula, S. selanica dan S. mecistopteryx sampai dengan umur 13 tahun, belum berpengaruh pada pertumbuhan riap tinggi maupun riap diameter.

2. Jenis tanaman hanya berpengaruh pada pertumbuhan riap diameter, dimana jenis S. leprosula telah mencapai diameter rata-rata $26,3 \mathrm{~cm}$ dan berbeda dibandingkan dengan jenis $S$. selanica yang baru mencapai rata-rata $21,4 \mathrm{~cm}$ dan $S$. mecistopteryx yang mencapai diameter rata-rata sebesar $20,7 \mathrm{~cm}$.

3. Volume kayu terbesar untuk setiap individu pohon berdiri diperoleh dari jarak tanam $3 \mathrm{~m} \times 3 \mathrm{~m}$ dengan rata-rata sebesar $0,318 \mathrm{~m}^{3}$ untuk jenis $S$. leprosula; $0,291 \mathrm{~m}^{3}$ jenis S. mecistopteryx dan S. selanica $0,275 \mathrm{~m}^{3}$.

4. Dengan perkiraan tanaman yang tumbuh sebanyak 50 persen, maka volume kayu tegakan terbesar diperoleh dari jarak tanam $3 \mathrm{~m}$ x $2 \mathrm{~m}$ dari jenis $S$. leprosula yaitu sebesar $240 \mathrm{~m}^{3}$ dibandingkan dengan jarak $3 \mathrm{~m}$ x $3 \mathrm{~m}$ hanya sebesar $175 \mathrm{~m}^{3}$. Demikian juga pada jenis S. mecistopteryx, volume pada jarak tanam $3 \mathrm{~m}$ x $2 \mathrm{~m}$ sebesar $226 \mathrm{~m}^{3}$ dan $3 \mathrm{~m} \times 3 \mathrm{~m}$ sebesar $160 \mathrm{~m}^{3}$ dan untuk jenis $S$. selanica pada jarak tanam $3 \mathrm{~m}$ x $2 \mathrm{~m}$ sebesar $209 \mathrm{~m}^{3}$ dan pada jarak tanam $3 \mathrm{~m} \times 3 \mathrm{~m}$ sebesar $161 \mathrm{~m}^{3}$.

\section{B. Saran}

1. Jenis S. leprosula dapat dikembangkan pada pembangunan Hutan Tanaman Industri maupun Hutan Tanaman Rakyat dengan jarak tanam $2 \mathrm{~m}$ x $3 \mathrm{~m}$.

2. Peneliti jarak tanam perlu dilanjutkan pada umur 20 tahun untuk mengetahui pengaruh jarak tanam pada pertumbuhan, dan atau perlakuan penjarangan dan aspek-aspek ekologi serta dampaknya pada lingkungan. 


\section{DAFTAR PUSTAKA}

Daryadi, L. dan Hardjono. 1972. Sendi-sendi Silvikultur. Direktorat Jenderal Kehutanan, Jakarta. Hal $60-61$.

Departemen Kehutanan. Direktorat Jenderal Bina Produksi Kehutanan 2010. Profil Sistem Silvikultur Intensif di Unit Manajemen Model : Konsep dan Implementasi.

Direktorat Jenderal Kehutanan, 1976. Vademecum Kehutanan Indonesia, Direktorat Jenderal Kehutanan . Departemen Pertanian.

Effendi, R dan A. Bachtiar. 1991. Pengaruh Jarak Tanam Terhadap Pertumbuhan Diameter dan Tinggi Pohon Bakau (Rhizophora apiculata) di Tembelihan, Riau. Bulletin Penelitian Hutan. Nomor 540. Hal 35 - 44.

Harbagung. 1996. Model Pertumbuhan Diameter dan Tinggi Tanaman Eucalyptus deglupta B1. Di Benakat Sumatera Selatan dan Kenangan Kalimantan Timur. Buletin Penelitian Hutan. No. 599. Hal $15-32$.

Kustiawan, W. dan M. Sutisna. 1989. Beberapa Aspek Teknis Penanaman dan Pemeliharaan Hutan Tanaman Industri. German Forestry Group Report No. 12. Hal 1 - 36.

Kuswanhandi dan Boerhandy 1996. Pengaruh jarak tanam terhadap pertumbuhan Hutan Tanaman Industri jenis karet di Jambi. Ekspose Hasil Penelitian Balai Penelitian Kehutanan Palembang.

Masano. 1991. Percobaan Penanaman Shorea johorensis dalam berbagai lebar jalur di kebun percobaan haurbentes, Jawa Barat. Buletin Penelitian Hutan. No. 540. Hal 25 - 34.

Nyland, R. D. 1996. Silviculture Concepts and Applications. The Grow-Hiel Companies. P $126-127$.

Rudjiman dan T. Andriyanti. 2002. Identification Manual of Shorea Species. Faculty of Forestry Gajah Mada University. Yogyakarta. 56 A.

Soekotjo ,2006. Langkah-Langkah dan Kemajuan Dalam Melaksanakan Silvikultur Intensif di 6 IUPHHK Model.Dep Kehutanan Tidak Diterbitkan

Soekotjo dan P. Raharjo. 2011. Era II Silin dan Status Tanaman Yang Dibangunnya. Fakultas Kehutanan Universitas Gajah Mada Yogyakarta. Tidak Diterbitkan.

Soemarna, K dan Harbagung. 1988. Penjarangan Pada Hutan Tanaman Industri. Prosiding Diskusi Hasil Penelitian Silvikultur Jenis Kayu Hutan Tanaman Industri. Badan Litbang Kehutanan. Jakarta. Hal $341-367$. 
Subiakto, A, Sunaryo dan H.S. Nurohniah. 2002. Pengembangan Meranti Bintang oleh Puslitbang Hutan dan Konservasi Alam. Silvatropika. Balitbang Kehutanan. Jakarta. Hal 5 -6. 